\title{
GENERALIZED WEIGHTED INEQUALITY WITH NEGATIVE POWERS
}

\author{
A. Kufner, K. Kuliev, J. A. Oguntuase and L.-E. Persson
}

Abstract. In this paper necessary and sufficient conditions for the validity of the generalized Hardy inequality for the case $-\infty<q \leqslant p<0$ and $0<p \leqslant q<1$ are derived. Furthermore, some special cases are considered.

Mathematics subject classification (2000): 26D10, 26D15, 47B38.

Key words and phrases: Inequalities, Hardy-type inequalities, weights, scales of weight characterizations, negative powers, duality.

\section{REFERENCES}

[1] A. Kufner And K. Kuliev, The Hardy inequality with negative powers, Adv. Alg. Anal. 1 (3) (2006), $1-10$.

[2] A. Kufner And L.E. Persson, Weighted Inequalities of Hardy Type, World Scientific Publishing Co, New Jersey/London/Singapore/Hong Kong, 2003.

[3] A. Kufner, L. Maligranda And L.-E. Persson, The Hardy Inequality - About its History and Some Related Results, Vydavatelsky Servis Publishing House, Pilsen, 2007.

[4] D. V. Prokhorov, Weighted Hardy's inequalities for negative indices, Publ. Mat. 48 (2004), 423-443. 